\section{(6) OPEN ACCESS}

\title{
Smoking and intention to quit in deprived areas of Glasgow: is it related to housing improvements and neighbourhood regeneration because of improved mental health?
}

\author{
Lyndal Bond, ${ }^{1}$ Matt Egan, ${ }^{1}$ Ade Kearns, ${ }^{2}$ Julie Clark, ${ }^{2}$ Carol Tannahill ${ }^{3}$
}

\begin{abstract}
${ }^{1}$ Evaluating the Health Effects of Social Interventions, MRC/CSO Social and Public Health Sciences Unit, Glasgow, UK ${ }^{2}$ Urban Studies, University of Glasgow, Glasgow, UK ${ }^{3}$ Glasgow Centre for Population Health, Glasgow, UK
\end{abstract}

\section{Correspondence to} Professor Lyndal Bond, Evaluating the Health Effects of Social Interventions, MRC/CSO Social and Public Health Sciences Unit, 4 Lilybank Gardens, Glasgow G128RZ, UK; I.bond@sphsu.mrc.ac.uk

Received 13 August 2012 Revised 24 October 2012 Accepted 30 October 2012 Published Online First 4 December 2012

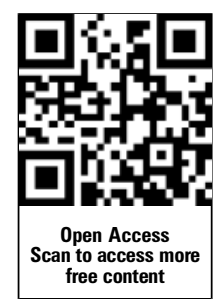

To cite: Bond L, Egan M, Kearns $\mathrm{A}$, et al. J Epidemiol Community Health 2013;67:299-304.

\section{ABSTRACT}

Background People living in areas of multiple deprivation are more likely to smoke and less likely to quit smoking. This study examines the effect on smoking and intention to quit smoking for those who have experienced housing improvements (HI) in deprived areas of Glasgow, UK, and investigates whether such effects can be explained by improved mental health.

Methods Quasi-experimental, 2-year longitudinal study, comparing residents' smoking and intention to quit smoking for $\mathrm{HI}$ group ( $n=545)$ with non-HI group ( $n=517)$, adjusting for baseline (2006) sociodemographic factors and smoking status. SF-12 mental health scores were used to assess mental health, along with selfreported experience of, and General Practitioner (GP) consultations for, anxiety and depression in the last 12 months.

Results There was no relationship between smoking and $\mathrm{HI}$, adjusting for baseline rates $(\mathrm{OR}=0.97,95 \% \mathrm{Cl}$ 0.57 to $1.67, p=0.918)$. We found an association between intention to quit and $\mathrm{HI}$, which remained significant after adjusting for sociodemographics and previous intention to quit (OR 2.16, 95\% Cl 1.12 to $4.16, p=0.022$ ). We found no consistent evidence that this association was attenuated by improvement in our three mental health measures. Conclusions Providing residents in disadvantaged areas with better housing may prompt them to consider quitting smoking. However, few people actually quit, indicating that residential improvements or changes to the physical environment may not be sufficient drivers of personal behavioural change. It would make sense to link health services to housing regeneration projects to support changes in health behaviours at a time when environmental change appears to make behavioural change more likely.

\section{INTRODUCTION}

Smoking is strongly socially patterned in industrialised nations. ${ }^{1-3}$ For example, the rate of smoking in the most deprived decile of areas in Scotland is more than four times that of smokers in the least deprived decile (44\% vs 9\% in 2009/2010), ${ }^{4}$ with similar differences by income reported in England and Wales-14\% of males in the highest income quintile households versus $40 \%$ males for lowest income quintile households. ${ }^{5}$ Smoking is related to individual factors such as low educational attainment and unemployment ${ }^{167}$ and to area-level or neighbourhood factors. ${ }^{2} 89$
Smokers living in areas of multiple deprivation are also less likely to quit smoking. ${ }^{10} 11$ This may be due to a number of factors such as barriers to accessing cessation programmes; ${ }^{12}$ more deep-rooted reasons for smoking in the first place, such as having to deal with undesirable environments and circumstances, and coping with stress; ${ }^{13}{ }^{14}$ or being exposed to more pro-smoking factors at the personal and community levels, such as cigarettes being more available, social norms more supportive and more permissive attitudes. ${ }^{15} 16$

Such explanations (where people live and the stressors in their lives) have led to considerations about whether making changes to residential environments might influence or impact smoking rates. Physical regeneration of neighbourhoods, including housing improvements (HI), has often been considered as a means of improving the physical and mental health and health behaviours of those living in deprived neighbourhoods, although the evidence for such impacts is limited and not always in the direction expected. ${ }^{17-20}$ Moreover, Thomson et al's ${ }^{18} 19$ systematic reviews indicate that targeted $\mathrm{HI}$ are more likely than area-level regeneration to affect general/physical and mental health. Indeed, $\mathrm{HI}$ focussed on improving warmth and security had the greatest impact on improved health.

One of the largest health effects reported from HI has been a reduction in smoking. ${ }^{21}$ Blackman et al s' $^{21} 5$-year follow-up of 98 households and 209 participants reported $50 \%$ reduction in smoking for those who had received a HI compared to those who did not. That is, $25 \%$ of residents who had a HI were smokers 5 years later compared to $75 \%$ of residents who had not had a HI, The authors proposed this reduction might be due to decrease in stress but were unable to demonstrate this proposed relationship in their study. This is an unusually large effect which if generalisable would clearly have important public health implications. Hence it is surprising that we know of no other published study that has used quasi-experimental methods to test potential causal pathways or measure the impact of HI on smoking.

In the housing and regeneration field there is a dearth of studies considering the impacts of renewal activities on the processes/stages of behaviour change. In fact, behaviour change theories such as Prochaska and DiClemente's Stages of Change ${ }^{22}$ model, which was originally developed in relation to smoking cessation, have been criticised for focussing solely on individuals and emphasising a process 
of cognitive shifts and developing behavioural intentions, ${ }^{23}$ while ignoring other factors. In particular, environmental factors do not feature in such theories, nor the possibility that 'life events' such as significant changes in people's residential circumstances could play a role in helping to move people from contemplation to action, or at an earlier stage shift them towards contemplation about behaviour changes, such as reducing or quitting smoking. This notion of residential change as a component of behaviour change is something we wish to explore here.

\section{Aims}

In this paper we use a 2-year follow-up study, to examine the effect on smoking and on intention to quit smoking for those who experienced HI compared with those who had not received such improvements, in Glasgow, UK. We have two questions:

1. does having a HI lead to a reduction in smoking or to an intention to quit smoking? and if yes,

2. could this be explained by improvements in mental health and/or reductions in stress subsequent to the HI?

\section{METHODS}

This paper uses data from GoWell, a long-term study of deprived communities in Glasgow undergoing major housing investment and area regeneration over a $10-15$ year period. ${ }^{24}$

\section{Setting}

The data are from 14 disadvantaged neighbourhoods in the city of Glasgow (UK). All the neighbourhoods fell below the lowest $15 \%$ income deprivation cut-off of the Scottish Index of Multiple Deprivation used to define area poverty by the Scottish Government. $^{25}$

\section{Data collection}

Data from the 14 neighbourhoods were collected in 2006 (wave 1) and 2008 (wave 2). Fieldwork for both the survey waves took place from May to July. Addresses were selected at random from the Post Office postal addresses file at each wave, although in some smaller neighbourhoods all residential addresses were selected. One adult householder (aged 16 years or over) per household was randomly sampled and, following informed consent, participated in a face-to-face interview. Full details of the questions asked have been published in the GoWell protocol. $^{24}$

\section{Identifying the cohort}

This paper draws on a prospective, longitudinal sample achieved pragmatically by using record linkage to identify participants who took part in cross-sectional studies conducted in 2006 and 2008 in the same neighbourhoods. The wave 1 cross-sectional survey achieved 6008 interviews (50.2\% response). The wave 2 cross-sectional survey achieved 4657 interviews $(47.5 \%$ response). The longitudinal sample was identified retrospectively using record linkage. From this process 1062 participants were identified as taking part in both surveys.

\section{Ethics}

Ethics approval was received from National Health Service (NHS) Scotland B Multiple Research Ethics Committees (MREC) committee in 2005 (no. 05/MRE10/89). All participants gave written informed consent. Data were recorded, transported and stored in accordance with data protection principals, ethical requirements and UK Medical Research Council guidance.

\section{Measures}

$\mathrm{HI}$ intervention and comparison groups

In 2008, participants were asked if they had experienced a HI in the last 2 years. The HI programme includes internal and external refurbishment of homes based on surveyors' assessments of each property. Examples include improvements to roofs, external cladding, doors, windows, bathrooms, kitchens, heating and rewiring/electrical repairs. ${ }^{26}$ The HI group was defined as having had such an improvement between 2006 and 2008. The non-HI group were householders residing in the same neighbourhood who did not report a HI between 2006 and 2008.

Smoking and intention to quit

At both waves $(2006,2008)$ participants were asked if they: smoked regularly now, smoked occasionally, no longer smoked or had never smoked. Responses were categorised as smoker (currently a regular or occasional smoker) or non-smoker (never smoked, had quit smoking). Smokers were also asked if they intended to give up smoking sometime in the future (coded as yes or no).

Assessment of mental health, stress, anxiety and depression We had three ways of assessing mental health:

1. SF-12v2: We used the mental health scale of the SF-12v2 Health Survey. The mental health composite score was computed using the scores of 12 questions in accordance with SF-12v2 procedure (Ware et al, 2000). Scores ranged from 0 to 100 , where a zero score indicated the lowest level of health and 100 indicated the highest level health. ${ }^{27}$ The time period for these questions was 'over the last 4 weeks'.

2. Consulted a doctor about mental health problems: Participants were also asked: '... in the past 12 months, have you spoken to a General Practitioner (GP) or a family doctor on your own behalf, either in person or by telephone about being anxious or depressed or about mental, nervous or emotional problems (including stress)'

3. Experience of anxiety/depression or stress: from a list of symptoms we asked participants if they had experienced stress, anxiety or depression regularly during the past year and if so had this improved, stayed the same or become worse. This question was asked in wave 2 (2008) only.

\section{Sociodemographic variables}

We included the following sociodemographic factors in our analysis: gender, ethnicity, age and educational attainment. Economic status was defined as economically active or not. We also included type of dwelling (house, flat, multistorey flat (MSF)) and whether the respondent rented or owned the dwelling. These housing variables were included because the degree of change and impact of HI could vary between dwelling types and tenures. ${ }^{28}$

\section{Method of analysis}

Logistic regression was used to assess the associations between $\mathrm{HI}$ and smoking and intention to quit smoking. Further logistic regressions examined whether the inclusion of mental health (by each of the three assessments) attenuated associations. For all analyses clustering of individuals within GoWell areas was adjusted for using robust standard errors. Regression was used to examine the relationship between $\mathrm{HI}$ and mental health as 
measured by the SF-12. STATA Version $\mathrm{X}$ was used for all analyses. $^{29}$

\section{RESULTS}

Of the 1062 in the study, 545 (51.3\%) reported having received a $\mathrm{HI}$ in the last 2 years. Table 1 shows there was little difference between those who had a HI (HI group) and those who did not (non-HI group) in terms of sociodemographic factors. More

Table 1 Sociodemographic variables, health and smoking status for those who had an improvement between 2006 and 2008 with those who did not

\begin{tabular}{|c|c|c|c|c|c|}
\hline & \multicolumn{4}{|c|}{$\begin{array}{l}\text { Housing improvement in last } \\
2 \text { years }\end{array}$} & \multirow[b]{3}{*}{$p$ Value } \\
\hline & \multicolumn{2}{|l|}{ No } & \multicolumn{2}{|l|}{ Yes } & \\
\hline & $n=517$ & $\%$ & $n=545$ & $\%$ & \\
\hline \multicolumn{6}{|l|}{ Gender } \\
\hline Male & 186 & 36.0 & 219 & 40.2 & 0.158 \\
\hline Female & 331 & 64.0 & 326 & 59.8 & \\
\hline \multicolumn{6}{|l|}{ Age } \\
\hline $16-24$ & 23 & 4.45 & 19 & 3.5 & 0.181 \\
\hline $25-39$ & 148 & 28.6 & 137 & 25.1 & \\
\hline $40-54$ & 128 & 24.8 & 142 & 26.1 & \\
\hline $55-64$ & 81 & 15.7 & 75 & 14.7 & \\
\hline $65+$ & 136 & 26.3 & 166 & 30.5 & \\
\hline \multicolumn{6}{|l|}{ Education } \\
\hline No qualifications & 433 & 83.75 & 464 & 85.14 & 0.533 \\
\hline GCSE A-C or above & 84 & 16.25 & 81 & 14.86 & \\
\hline \multicolumn{6}{|l|}{ Economically active } \\
\hline Yes & 184 & 51.98 & 185 & 52.26 & 0.940 \\
\hline No & 170 & 48.02 & 169 & 47.74 & \\
\hline \multicolumn{6}{|l|}{ Citizenship } \\
\hline British & 438 & 84.72 & 442 & 81.1 & 0.118 \\
\hline Non-British & 79 & 15.28 & 103 & 18.9 & \\
\hline \multicolumn{6}{|l|}{ House type } \\
\hline MSF & 252 & 58.93 & 350 & 64.34 & $<0.001$ \\
\hline Other flat & 186 & 36.12 & 143 & 26.29 & \\
\hline House & 77 & 14.95 & 51 & 9.38 & \\
\hline \multicolumn{6}{|l|}{ Tenure } \\
\hline Owned & 106 & 20.5 & 65 & 11.93 & $<0.001$ \\
\hline Rented & 411 & 79.5 & 480 & 88.07 & \\
\hline \multicolumn{6}{|l|}{ Health } \\
\hline Longstanding illness (2006) & 146 & 28.2 & 153 & 28.1 & 0.952 \\
\hline \multicolumn{6}{|l|}{ Mental health } \\
\hline SF-12_MH (2006) & 47.41 & 10.03 & 48.29 & 9.83 & 0.149 \\
\hline SF-12_MH (2008) & 46.87 & 9.65 & 49.21 & 9.68 & $<0.001$ \\
\hline \multicolumn{6}{|c|}{ Visited doctor in last 12 months for anxiety/depression } \\
\hline 2006 & 113 & 21.9 & 101 & 18.5 & 0.377 \\
\hline 2008 & 114 & 22.3 & 114 & 20.9 & 0.859 \\
\hline \multicolumn{6}{|c|}{ Experienced mental health problems regularly in previous 12 months (2008) } \\
\hline No & 449 & 86.9 & 461 & 84.6 & 0.578 \\
\hline Yes, but improved & 8 & 1.6 & 10 & 1.8 & \\
\hline Yes, problems the same & 30 & 5.8 & 43 & 7.9 & \\
\hline Yes, problems worse & 30 & 5.8 & 31 & 5.7 & \\
\hline \multicolumn{6}{|l|}{ Smoking and intention to quit } \\
\hline Current smoker (2006) & 250 & 48.4 & 208 & 38.2 & $<0.001$ \\
\hline Current smoker (2008) & 253 & 48.9 & 218 & 40.0 & 0.003 \\
\hline Intention to quit (2006) & 146 & 58.4 & 114 & 54.8 & 0.440 \\
\hline Intention to quit (2008) & 90 & 35.6 & 114 & 52.3 & $<0.001$ \\
\hline
\end{tabular}

GCSE, General Certificate of Secondary Education; MH, Mental health; MSF, multi-storey flats. people who had a HI lived in MSF and more rented their dwellings (as expected given the nature of the intervention described above), but the differences between the groups on these characteristics were not large $(<10 \%)$.

The HI group reported better mental health as assessed by the SF-12MH scale than the non-HI group in 2008, with no significant differences in 2006. There were no significant differences between the two groups for the other two mental health assessments.

\section{Smoking prevalence and intention to quit}

Table 1 also contains prevalence rates for smoking and intention to quit in the HI and non-HI groups. There was a significant difference in smoking prevalence between the two groups in 2008 (40\% vs $48 \%$, OR $0.69695 \%$ CI 0.53 to $0.91, \mathrm{p}=0.010$, respectively). This mirrored the $10 \%$ difference in prevalence between the two groups at baseline rather than reflecting a significant difference associated with $\mathrm{HI}$ (OR for $\mathrm{HI}$ reduced to $0.97,95 \%$ CI 0.57 to $1.67, p=0.918$ when adjusting for smoking at baseline).

With respect to intention to quit there was a small but not significant difference at baseline (2006) between the two groups. However, a significantly greater number of those in the HI group stated they intended to quit in 2008 than those in the non-HI group (52\% vs $36 \%$ respectively); as table 1 shows, intention to quit fell substantially in the non-HI group $(-23 \%)$, but fell only marginally in the HI group $(-3 \%)$. Table 2 presents the univariate and multivariate logistic regressions. HI participants were twice as likely to intend to quit smoking as the non-HI group and this

Table 2 Univariate and multivariate regressions for expressed intention to quit smoking in 2008, having a housing improvement $(\mathrm{HI})<2008$, and sociodemographic factors $(\mathrm{N}=417)$

\begin{tabular}{|c|c|c|c|}
\hline & OR & $(95 \% \mathrm{Cl})$ & $\mathrm{p}$ Value \\
\hline \multicolumn{4}{|l|}{ Model 1} \\
\hline $\mathrm{HI}$ & 1.99 & 1.10 to 3.57 & 0.023 \\
\hline \multicolumn{4}{|l|}{ Model 2} \\
\hline \multicolumn{4}{|l|}{$\mathrm{HI}$} \\
\hline Yes & 2.16 & 1.12 to 4.16 & 0.022 \\
\hline \multicolumn{4}{|l|}{ Intend to quit 2006} \\
\hline Yes & 1.25 & 0.68 to 2.29 & 0.460 \\
\hline \multicolumn{4}{|l|}{ Gender } \\
\hline Female & 0.84 & 0.56 to 1.27 & 0.397 \\
\hline \multicolumn{4}{|l|}{ Citizenship } \\
\hline Non-British & 0.72 & 0.42 to 1.22 & 0.209 \\
\hline \multicolumn{4}{|l|}{ Employment (base inactive) } \\
\hline Employed & 1.03 & 0.64 to 1.65 & 0.910 \\
\hline Retired & 1.55 & 0.61 to 3.96 & 0.343 \\
\hline \multicolumn{4}{|l|}{ Tenure } \\
\hline SR & 0.90 & 0.46 to 1.77 & 0.761 \\
\hline \multicolumn{4}{|c|}{ Education attainment (no school qualification) } \\
\hline School qualification or more & 1.08 & 0.64 to 1.87 & 0.748 \\
\hline \multicolumn{4}{|l|}{ Age-base $16-24$} \\
\hline $25-33$ years & 2.21 & 0.53 to 9.29 & 0.526 \\
\hline $40-54$ years & 2.42 & 0.49 to 11.93 & 0.266 \\
\hline $55-64$ years & 1.74 & 0.37 to 8.26 & 0.476 \\
\hline $65+$ years & 0.60 & 0.11 to 3.35 & 0.549 \\
\hline \multicolumn{4}{|l|}{ Built form (base is MSF) } \\
\hline Other flats & 2.19 & 1.06 to 4.53 & 0.031 \\
\hline House & 2.87 & 1.22 to 6.64 & 0.017 \\
\hline
\end{tabular}

MSF, multi-storey flats. 
association remained significant with the inclusion of the sociodemographic variables and prior statement of intention to quit (2006).

\section{Does improvement in mental health help to explain the relationship between $\mathrm{HI}$ and intention to quit?}

The previous analyses have examined the relationships between $\mathrm{HI}$ and smoking. Our second question was whether, if we found an association between $\mathrm{HI}$ and smoking or intending to quit smoking, this might be explained by an improvement in mental health or reduction in experiencing depression, anxiety or stress.

To address this second question we focus on the relationship between HI, mental health and intention to quit. This is because the previous analyses showed no association between current smoking and having received a $\mathrm{HI}$ (adjusting for previous smoking status), but it did find an association between intention to quit smoking and a HI, and an association between improved mental health and HI.

To examine whether improvements in mental health attenuate the relationship between $\mathrm{HI}$ and intention to quit smoking, table 3 presents four multivariate models examining the association between $\mathrm{HI}$ and intention to quit and the three assessments of mental health. All models are adjusted for sociodemographic factors and also adjusted for the appropriate 2006 health measure (eg, for SF-12 Mental health (MH) 2008, we have adjusted for participants SF-12 MH 2006 scores etc). The ORs for HI are reduced slightly in models 2-4, though a substantial effect of HI remains in each case. Mental health as measured by SF-12MH scale is negatively associated with intention to quit although this is not statistically significant. Consulting a GP about emotional problems in the last 12 months is strongly related to intention to quit but was not significantly associated with HI (see table 1). For the third assessment of mental health there is a strong association between experiencing an improvement in symptoms-and a

Table 3 Associations between $\mathrm{HI}$, the three mental health assessments and intention to quit smoking (2008)

\begin{tabular}{|c|c|c|c|}
\hline & \multicolumn{3}{|c|}{ Intend to quit smoking } \\
\hline & Adjusted OR & $(95 \% \mathrm{Cl})$ & $p$ Value \\
\hline \multicolumn{4}{|l|}{ Model $1 *$} \\
\hline House improvement & 2.16 & 1.12 to 4.14 & 0.022 \\
\hline \multicolumn{4}{|l|}{ Model $2 \dagger$} \\
\hline House improvement & 1.81 & 0.92 to 3.55 & 0.084 \\
\hline SF-12MH 2008 & 0.98 & 0.95 to 1.01 & 0.182 \\
\hline \multicolumn{4}{|l|}{ Model 3‡ } \\
\hline House improvement & 2.10 & 1.11 to 3.96 & 0.024 \\
\hline $\begin{array}{l}\text { GP consult for anxiety/ } \\
\text { depression in } 2008 \\
\text { (base is no GP consult) }\end{array}$ & 3.99 & 2.24 to 7.14 & $<0.001$ \\
\hline \multicolumn{4}{|l|}{ Model 4* } \\
\hline $\begin{array}{l}\text { House improvement } \\
\text { MH change (base is no }\end{array}$ & \multicolumn{2}{|c|}{$\mathrm{MH}$ change (base is no $\mathrm{MH}$ ) } & 0.077 \\
\hline Improved & 6.59 & 1.77 to 24.41 & 0.006 \\
\hline Same & 2.30 & 0.98 to 5.69 & 0.070 \\
\hline Worse & 2.25 & 0.98 to 5.17 & 0.054 \\
\hline \multicolumn{4}{|c|}{$\begin{array}{l}\text { *Adjusting for baseline demographics, intention to quit in } 2006 \text {. } \\
\text { †Adjusting for baseline demographics, intention to quit in } 2006 \text { and SF-12MH in } \\
2006 \text {. } \\
\text { ¥Adjusting for baseline demographics, intention to quit in } 2006 \text { and GP consultation } \\
\text { in } 2006 \text { for MH problems. } \\
\text { HI, housing improvement. }\end{array}$} \\
\hline
\end{tabular}

marginally statistically significant association between symptoms remaining the same or becoming worse-and intention to quit smoking. Again, however, these are not associated with HI.

In summary:

1. mental health as measured by SF12-MH was positively associated with having a $\mathrm{HI}$ but negatively associated with intention to quit smoking

2. consulting a GP about emotional problems in the last 12 months was not associated with having a HI but was positively associated with intention to quit smoking

3. experiencing an improvement in depression/anxiety symptoms was associated with intention to quit smoking but not with HI.

\section{DISCUSSION}

\section{Smoking rates}

There was a significant difference in the prevalence of smoking at baseline (2006) between the two groups, with smoking rate $10 \%$ lower among those who subsequently received a HI. Note that in both cases, the smoking rate was well above the national norm of $26 \%$ for men and $23 \%$ for women. ${ }^{4}$ However, this difference in prevalence at baseline was likely due to chance or factors not related to receiving HI. HI are provided on an area or property basis (buildings needing improvements), not on householder characteristics, nor are they provided in response to householders' proactively seeking HI. We do not believe that residents are provided with $\mathrm{HI}$ on the basis of their smoking status, or that non-smokers were able to proactively seek these improvements.

Our findings are in stark contrast to those by Blackman et $a l^{21}$ who reported a very large reduction in the prevalence of smoking for those receiving some type of housing renewal. However, there are some key differences between that study and the one reported here. On the one hand, the Blackman study reported on a 5 year follow-up and perhaps one needs to allow for more time to see any effects on smoking, though we do not think this is likely. On the other hand, their study was small and therefore limited in its capacity to adjust for confounders and it did not take account of the clustered nature of their data: 98 households, 209 respondents. Our study is larger and includes a greater proportion of people in relatively poor circumstances, who are more likely to smoke and less likely to be successful at quitting.

\section{Intention to quit}

While we found no reduction in smoking rates for those who had an HI, we found differences between the $\mathrm{HI}$ and non-HI groups regarding their intention to quit smoking, with the HI group significantly more likely to have an intention to quit. These differences were not explained by baseline differences in intention to quit. We also found no evidence that the mechanism by which HI might operate on residents' intention to quit smoking was via improvement in mental health or reduction in stress, as proposed by Blackman et al. ${ }^{21}$ Thus while we found a positive association between having a $\mathrm{HI}$ and improved mental health (as measured by SF-12) which is congruent with previous research, ${ }^{19}$ those in our study who stated an intention to quit smoking had worse mental health scores in 2008 than 2006, using the SF-12 MH measure (although this was not statistically significant). Seeking GP advice and/or experiencing mental health problems regularly, whether these improved, stayed the same or worsened, were independently associated with a higher likelihood of intention to quit. The former may be due to GPs giving brief motivational advice to quit, or it may reflect a greater general tendency/ability to take action among this group. 


\section{Why might $\mathrm{HI}$ influence people's intentions to quit smoking, if not via improved mental health?}

A possible explanation for $\mathrm{HI}$ to motivate people to (plan) to quit might be via increased optimism through actual or anticipated improvement in life circumstances. ${ }^{16} 3031$ Studies of weight loss and smoking cessation show that such health behaviour changes can be triggered by positive or negative life events, crises or medical triggers. ${ }^{16} 23031 \mathrm{HI}$ is likely to be experienced by residents as an improvement in their circumstances, however such improvements do not radically change the area-level deprivation, or other aspects of the neighbourhood, nor do they radically change other life circumstances. This is perhaps why we find intention to quit related to $\mathrm{HI}$ but not quitting-insufficient change in life circumstances. We note that Blackman et al, ${ }^{21}$ were also unable 'to establish any evidence that neighbourhood renewal contributed to the decline [in smoking]' (p.580).

Our findings can be seen as lending support to Blackman's ${ }^{30}$ proposed theory of change and his suggestion that smoking cessation programmes might usefully target 'points of transition' in people's lives. Similarly, West and Sohal ${ }^{23}$ propose '... that beliefs, past experiences, and the current situation create varying levels of 'motivational tension,' in the presence of which even quite small 'triggers' can lead to a renunciation of smoking; where they lead instead to a 'plan' for later action, this may signify a lower level of commitment in a proportion of smokers'. They call on public health campaigns to '.. . perhaps focus on ... creating motivational tension; triggering action in smokers who are on the 'cusp' of a change ...; and ensuring the immediate availability of treatment ... to support those attempts. ( $\mathrm{p} 460)$

We would argue that a radical change in someone's residential circumstances such as a move to a new home or having their existing home substantially improved might constitute such a 'point of transition' or 'cusp of change' as suggested above, and therefore counselling and support for smokers could be usefully provided as part of a more holistic HI programme. What we cannot tell from the current study is how HI might act as part of a behavioural change process. The effect could be due to one or more of the following factors identified in theories of behavioural change $\left(\right.$ see $^{32} 33$ ): self efficacy-a greater belief in one's ability to achieve change, especially if a resident had been waiting for home improvements for some time; environmental opportunity-the view that stopping smoking is somehow appropriate for a 'new' domestic environment; or reasoned action-the value placed on making wide-ranging changes to one's life to accompany the residential change. Our research on the interface between residential changes and health behavioural changes exemplifies the point made previously that theories of behavioural change need to consider the role of environmental and contextual factors as an integral part of their individualistic and psychological perspective on change. ${ }^{34} 35$

\section{Limitations}

The study has some limitations. The approach of linking records from two cross-sectional surveys has implications for the representativeness of the sample and possible selection bias. While this limitation is present for both groups in this study (ie, we have internal validity), the generalisability of our results might be limited. A further limitation of the study is the 2-year time span over which the HI were done. Some respondents may have had their HI 2 years ago, others 6 months ago or less from the time of the 2008 survey. We may therefore be losing some effects of the $\mathrm{HI}$ as the impact of the intervention might fade. Even so, if we are looking for long(ish)-term effects this may not be too much of an issue. In terms of our mental health measures we also have
What is already known on this subject

- Systematic reviews have suggested that housing improvement (HI) interventions have the potential to contribute positively to public health goals, including attempts to improve the health of disadvantaged groups. A previous study suggested that people are more likely to quit smoking after an improvement to their home. HI /urban regeneration has also been shown to have small effects on mental health and, it has been argued, could affect health behaviours through these changes to mental health.

\section{What this study adds}

- In contrast to an earlier study, we found that providing residents in disadvantaged areas with better housing did not lead to a reduction in smoking but housing improvement (HI) was associated with intention to quit. Improvements in mental health do not explain this association. HI may not be sufficient to significantly reduce smoking rates, but such improvements may provide a 'critical moment' for more targeted smoking interventions. Linking health services to housing regeneration projects might provide an opportunity to develop interventions that capitalise on this 'critical moment', although such interventions should be evaluated for effectiveness.

variation in the time scales we asked about. The SF-12MH asks about the past 4 weeks, the other two measures ask about the last 12 months. The numbers who reported regular mental health problems were quite small, and the numbers who reported improvements were very small, limiting the precision of effect estimates for this. This question about change in symptoms also did not take severity into account-those with severe problems which have improved would have been grouped with those with mild problems which have also improved.

\section{Strengths}

The major strengths of this study are its quasi-experimental design, longitudinal data on a relatively large sample, and the capacity to adjust for possible baseline confounders. This allows us to begin to consider causal pathways and mechanisms.

\section{Implications}

Given the well known strong association between smoking and community disadvantage and the structural and social barriers in place in these communities to cease smoking, it is not sufficient to try to change people's behaviour by focussing on individual characteristics and seeing behaviour change as a deliberative process (as is the case in most social-psychological models of behaviour). Wider influences need to be recognised. This study indicates that providing residents in disadvantaged areas with better housing may prompt them to consider quitting smoking. However, few people actually quit, indicating that residential improvements or changes to the physical environment may not be sufficient drivers of personal behavioural change. It would make sense to link health services to housing regeneration projects to encourage/support changes in health behaviours at a time when environmental change appears to make behavioural change more likely. 
Contributors LB led the design of the paper, undertook the analysis and wrote the first draft. ME made substantial contributions to the concept, acquisition of the data and interpretation. AK made substantial contributions to the concept, design, acquisition of the data and interpretation. JC made contribution to analysis and interpretation. CT made substantial contributions to the concept, design, acquisition of the data and interpretation. All authors contributed intellectual content to the final draft and will contribute to final approval when published.

Funding GoWell is funded by the Scottish Government, NHS Health Scotland, Glasgow, Housing Association, Glasgow Centre for Population Health, NHS Greater Glasgow and Clyde. LB and ME are funded by the Chief Scientist Office at the Scottish Government Health Directorate as part of the Evaluating Social Interventions programme at the MRC Social and Public Health Science Unit (U.130059812). AK and $\mathrm{JC}$ are funded by the University of Glasgow. CT is funded by NHS Greater Glasgow and Clyde.

Competing interests None.

Patient consent Obtained.

Ethics approval NHS Scotland B MREC committee.

Provenance and peer review Not commissioned; externally peer reviewed.

Open Access This is an Open Access article distributed in accordance with the Creative Commons Attribution Non Commercial (CC BY-NC 3.0) license, which permits others to distribute, remix, adapt, build upon this work non-commercially, and license their derivative works on different terms, provided the original work is properly cited and the use is non-commercial. See: http://creativecommons.org/ licenses/by-nc/3.0/

\section{REFERENCES}

1 Gray L, Leyland A. Is the "Glasgow effect" of cigarette smoking explained by socio-economic status? A multilevel analysis. BMC Public Health 2009;9:245.

2 Pickett KE, Pearl M. Multilevel analyses of neighbourhood socioeconomic context and health outcomes: a critical review. J Epidemiol Community Health 2001;55:111-22.

3 Laaksonen $\mathrm{M}$, Rahkonen $\mathrm{O}$, Karvonen $\mathrm{S}$, et al. Socioeconomic status and smoking. Eur J Public Health 2005:15:262-9.

4 Government S. Scotland's People Annual Report: results from the 2009/2010 Scottish Household Survey'. Edinburgh: Scottish Government, 2011.

5 Robinson S, Harris H. Smoking and drinking among adults, 2009 A report on the 2009 General Lifestyle Survey. 2011. http://www.esds.ac.uk/doc/6737\% $\%$ Cmrdoc\% 5Cpdf\%5C6737report.pdf (accessed 29 Nov 2012).

6 Lawlor DA, Batty GD, Morton SM, et al. Childhood socioeconomic position, educational attainment,and adult cardiovascular risk factors: the Aberdeen children of the 1950s cohort study. Am J Public Health 2005;95:1245-51.

7 Haustein KO. Smoking and poverty. Eur J Cardiovasc Prev Rehabil 2006;13:312-18.

8 Duncan C, Jones K, Moon G. Smoking and deprivation: are there neighbourhood effects? Soc Sci Med 1999:48:497-505.

9 Ellaway A, Macintyre S. Does where you live predict health related behaviours? A case study in Glasgow. Health Bull (Edinb) 1996;54:443-6.

10 Giskes $\mathrm{K}$, van Lenthe FJ, Turrell G, et al. Smokers living in deprived areas are less likely to quit: a longitudinal follow-up. Tob Control 2006;15:485-8.

11 Richardson K. Smoking, low income and health inequalities: thematic discussion document Report for Action on Smoking and Health and the Health Development Agency May 2001. 2001.

12 Roddy E, Antoniak M, Britton J, et al. Barriers and motivators to gaining access to smoking cessation services amongst deprived smokers-a qualitative study. BMC Health Serv Res 2006;6:147.

13 Graham H. When life's a drag: women, smoking and disadvantage. London, UK: HMSO, 1993.
14 Ellaway A, Macintyre S. Are perceived neighbourhood problems associated with the likelihood of smoking? J Epidemiol Community Health 2009;63:78-80.

15 Paul C, Ross S, Bryant J, et al. The social context of smoking: a qualitative study comparing smokers of high versus low socioeconomic position. BMC Public Health 2010:10:211.

16 Stead M, MacAskill S, MacKintosh A-M, et al. "It's as if you're locked in": qualitative explanations for area effects on smoking in disadvantaged communities. Health \& Place 2001;7:333-43.

17 Atkinson $\mathrm{R}$, Thomson $\mathrm{H}$, Kearns $\mathrm{A}$, et al. Giving urban policy its 'medical': assessing the place of health in area-based regeneration. Policy Polit 2006;34:5-26.

18 Thomson $\mathrm{H}$, Petticrew M, Morrison D. Health effects of housing interventions: a systematic review of intervention studies. BMJ 2001:323:187-90.

19 Thomson $H_{\text {, Thomas }}$, Sellstrom E, et al. The health impacts of housing improvement: a systematic review of intervention studies from 1887 to 2007. Am J Public Health 2009;99(S3):S681-92.

20 Jacobs DE, Brown MJ, Baeder A. A systematic review of housing interventions and health: introduction, methods, and summary findings. J Public Health Manag Pract 2010:16:S5-10.

21 Blackman T, Harvey J, Lawrence J, et al. Neighbourhood renewal and health: evidence from a local case study. Health Place 2001;7:93-103.

22 Prochaska JO, DiClemente CC. Toward a comprehensive model of change. Addictive Behaviors: Processes of Change. Miller WR, Heather N. New York, Plenum Press, 1986:3-27.

23 West R, Sohal T. Catastrophic" pathways to smoking cessation: findings from national survey. BMJ 2006:332.

24 Egan M, Kearns A, Mason P, et al. Protocol for a mixed methods study investigating the impact of investment in housing, regeneration and neighbourhood renewal on the health and wellbeing of residents: the GoWell programme. BMC Med Res Methodol 2010;10:41.

25 Walsh D. Health and wellbeing in Glasgow and the GoWell areas-deprivation based analyses. Glasgow: Glasgow Centre for Population Health, 2008.

26 GoWell. Progress for People and Places: Monitoring change in Glasgow's communities. Evidence from the GoWell Surveys 2006 and 2008. Glasgow: Glasgow Centre for Population Health, 2010.

27 Ware JE, Koninski M, Dewey JE. How to score version two of the SF-36 health survey. Lincoln, RI: Quality Metric Incorporated, 2000.

28 Clark J, Kearns A. Housing improvements, housing quality and psychosocial benefits from the home. Housing Studies, doi:10.1080/02673037.2012.725829.

29 Statacorp. Stata statistical software: release X. College Station, TX: StataCorp LP, 2007.

30 Blackman T. Can smoking cessation services be better targeted to tackle health inequalities? Evidence from a cross-sectional study. Health Educ J 2008:67:91-191.

31 Ogden J. A psychosocial model of behaviour change and role for life events. Eur Health Psychol 2009:14:30-2.

32 United States Secret Service and United States Department of E. The final report and findings of the safe school initiative: implications for the prevention of school attacks in the United States. Washington, D.C: United States Secret Service and United States Department of Education, 2002.

33 Family Health International. Behaviour change-summary of four major theories. 2007. http://www.fhi360.org/nr/rdonlyres/ei26vbs/psidmahhxc332vwo3g23 3xsqw22er3vofqurfjububyzclvajcbdgexyz|3msu4mn6xv5j/ bccsummaryfourmajortheories.pdf (accessed 8 Aug 2012).

34 Kippax S, Crawford J. Flaws in the theory of reasoned action. In: Terry DJ, Gallois C, McCamish M, eds. The theory of reasoned action: its application to AIDS preventive behavior. New York: Pergamon Press, 1993:253-69.

35 Vlaev I, Dolan P. From changing cognitions to changing the context: a dual-route model of behaviour change. Discussion Paper 4. London, UK, 2009. 